\title{
REFRAMING CHANGE: GENERATING NEW IMAGES THROUGH MULTIPLE LENSES
}

\author{
HELEN L. HARRINGTON
}

The University of Michigan, U.S.A.

\section{AN ESSAY-REVIEW OF THE CASE FOR CHANGE: RETHINKING THE PREPARATION OF EDUCATORS}

Seymour B. Sarason (1993). San Francisco: Jossey-Bass (ISBN 1-55542-504-6)

In The Case for Change: Rethinking the Preparation of Educators, Seymour B. Sarason continues his attempts to generate positive, substantive change in how students in our schools are educated. At the forefront of his argument is what Eisner (1993) set as the major target for future research in education, the improvement of education so that lives are enhanced and schools are better places for everyone involved. No matter what one sees as the aim of education, it is difficult to see schooling as successful on most measures, particularly for those students most neglected by society. Sarason's book does not build an argument about the need for change nor does he attempt to suggest in any detail what form change should take. What he does is focus our attention on the preparation of teachers. He shows how teacher education is an essential link in fundamentally reconceptualizing the schooling process. But, as I read Sarason's frequent references to other books he has written calling for change, I was left wondering whether we can change, or even worse, if we really want to change the way education is conducted in the U.S.A. If we genuinely desire change of the sorts Sarason has argued for, we must ask why previous "attempts" have not been particularly successful. Sarason suggests that one of the reasons for our lack of success is our failure to be more thoughtful about change. He charges that we frame our conception of change inappropriately, underestimate its complexity, and do not prepare educators for their role in change. In light of the argument he builds, these are charges it would be hard to deny.

\section{Framing Change}

Sarason uses the metaphor of primary prevention to frame his discussion of change. In doing so he makes use of a generative metaphor, one through "which new perspectives on the world come into existence" (Schon, 1979, p. 254). Just as Schon shows us how viewing the dilemma of urban housing as one of "blight and renewal" or as one of the "natural community and its dislocation" leads to very different approaches to its resolution, Sarason's reframing of educational reform as a dilemma of primary prevention rather than repair generates new possibilities. Sarason's reframing prompts a major philosophical shift, taking us from what is to what ought to be. This shift acknowledges the necessity of long-term investment, contextual complexity in change, and belief that education must "nurture and support in students their ever present curiosity and desire to understand themselves and the world we live in" (p. xiii). Reframing change as primary prevention also provides a 
lens for focusing our thinking about change and the difficulties we will encounter as we attempt to address two questions he continues to raise throughout the book: How can we prepare teachers who convey the joy and challenge in learning if they do not experience that in their own education? How can teachers effect change if they are not prepared to do so? Addressing these questions so central to Sarason's view invites consideration of four staging areas inherent in effective change: individuals, politics, the organization, and the culture.

\section{The Individuals in Change}

Sarason's discussion of the individuals who should be participants in primary prevention is inclusive. As other writers have suggested, he also suggests that scholars from other disciplines must be involved with educators in the reconceptulization of education. Whether this involvement focuses on the educational preparation of prospective teachers or in conceptualizing what it means to approach change in the schools as an issue of primary prevention, it will be necessary to use multiple lenses to gain a fuller understanding. Multiple perspectives are needed to grasp the full complexity of the change required and to gain insight into the radical rethinking that lays the foundation for prevention. I agree with Sarason. But I propose that he may vastly underestimate how difficult that rethinking will be for many of us. He uses a lens that he has ground and polished over a lifetime of work. He is suggesting a reconceptualization not only in how we approach educational reform but in how we approach all of our work. As Deal and Kennedy (1982) noted over a decade ago,

people form strong attachments to ... all the symbols of the work place. Change strips down these relationships and leaves (individuals) confused, insecure, and often angry ... Because of these cultural barriers to change, effecting real and lasting change is timeconsuming, costly, difficult, and risky. (p. 157)

Embracing a spectrum of non-educationists' perspectives on educational issues may be seen as particularly risky because it challenges our professional authority and expertise. It challenges, in fundamental ways, our sense of who we are.
Most of us are willing to accept that we do not have the "right" answers. Fewer of us are willing to accept that, as educators, we may have neither the best answers nor even adequate answers for problems perceived as primarily educational. Just as those prepared in the disciplines denigrate educators' contributions - an issue Sarason addresses - many of us in education question whether answers provided by individuals who have no direct experience with education (outside of the education all of us receive as students or the education we provide as faculty members in higher education) can be as valid as ours. But, if we attend to each other, a richer understanding for us all may evolve.

Eisner (1993) mirrors this issue so well.

If there are different ways to understand the world,
and if there are different forms that make such
understanding possible, then it would seem to follow
that any comprehensive effort to understand the
processes and outcomes of schooling would profit
from a pluralistic rather than a monolithic approach
.. How can such a pluralism be advanced? What
would it mean for the way we go about our work?
(p. 8)

Eisner's struggles with these questions make clear how difficult it will be to address them. Those of us in teacher preparation do not have to look very far to reveal the inherent difficulties. In teacher preparation programs examples of limited ways of understanding are the Educational Psychology courses that exclude child development because it is not viewed as a particularly appropriate lens or a programmatic overemphasis on content and methods because what seems to matter most is the subject to be taught and not the children. Uncovering such limitations in teacher preparation programs should not assuage our investigation of the possible limitations inherent in the liberal arts components of prospective teachers' education. Sarason's stress on involving individuals from all disciplines in the study of education seems as much a plea for educating the public about education (the future taxpayers, parents, and voters that college students will become) as it is to involve social scientists in our own efforts. His concern addresses dcep barricrs to truc reform. Although individuals can seriously undermine attempted change, it will take all of us working together to effect lasting, substantive change. All the stakeholders must not merely be acknowl- 
edged; their interests must be considered for it is this plurality that is one objective of education.

\section{The Politics of Change}

The individuals in change often reflect the politics of change. When asking ourselves who has power to effect change as well as who power to limit it, we must address issues of governance. Sarason looks at the multiple participants in education beyond teacher preparation programs - students, parents, teachers, administrators and suggests that, there too, our thinking is often limited and too narrow. He asks how often those preparing to be teachers and those preparing to be administrators are made aware of the perspectives of the other. He addresses how the power imbalance we often see in schools is carried into teachers' relationships with students and parents. To encourage students and parents as active participants in the schooling process may require teachers who are themselves active participants, not only in the governance of schools, but in their own education as well. Sarason does not build his argument on issues of professionalism as much as he does on what is, in the long run, best for students. He keeps at the forefront of this discussion the enhancement of the lives of all students, finding ways to nurture conditions wherein they "can experience a sense of learning, growth, and personal and intellectual change for themselves" (p. xiv).

He sustains this impassioned focus throughout and makes clear how our relationship with prospective teachers ultimately will be reflected in the classrooms and schools they inhabit. He comes back again and again to admonish that, just as we cannot blame present educators for the current condition of schools, such as power relationships that are too often hierarchical, we can no longer rely on repair rather than prevention. It is not possible to reconceptualize schools totally only by working with today's educators. Rather, we must work with tomorrow's educators within the context of our teacher preparation programs. The next question then becomes, What is each of us doing to not only prepare our students for the power and the politics in schools as they are but, more importantly, for changing those balances? If teachers do not have power now it does not mean they cannot have power in the future. These new responsibilities will, according to Sarason, require attitudes, knowledge, and understanding that most prospective teachers are not now developing in their teacher preparation programs. Such changes in attitudes, knowledge, and understanding will be necessary to increase not only teachers' power but the power of students and parents. If the ideal of a democratic community is an aim, each participant must be given a voice, a voice that is heard. As Sarason argues, in working together to resolve our educational dilemmas, our resolutions become more just and equitable for all of us.

\section{The Organizational Context}

The organizational context of education seems to mitigate change. Although, in this book, Sarason does not discuss directly the constraints on change attributable to the structure of educational organizations, it is clear throughout his discussions that he does not underestimate these factors - nor should we. Individuals' and politics' involvement in change are refiections of education's organization - relationships among the work of teachers and administrators, the scope of teacher empowerment, and the ecology of structures of governance. Examination of each, as they manifest themselves in schools, tells us much about the organization. In addition, we must consider how the organization of schools does or does not provide opportunities for addressing the interests of other stakeholders students, parents, and members of the community. As Sarason indicates, one of the most serious requirements for effecting lasting, substantive change is to recognize and work with the interests of various stakeholders. Individual teachers working in isolated classrooms does not bode well for effecting lasting change.

Sarason claims we know much less about how schools can be effectively organized to support necessary changes than we do about aspects of school organization that limit the chance for effective change. He suggest we not only pay more attention to alternative schools that have been successful but that we do a better job of documenting the process. As he indicates,

We need to know the leadership, constituencies, resources, organizational style, development and 
transformations, time perspectives, mistakes, serendipity, personnel selection and turnover - factors that make up a complicated narrative that should seek less to persuade than to force us to conclude that we are being given a no-holds-barred, wartsand-all account that tells us what happened when visions power actions. (p. 39)

Although Sarason begins the book with a discussion of The Story of the Eight-Year Study with Conclusions and Recommendations (Aikin, 1942) he barely acknowledges other investigations of organizational change, educational or otherwise. Missing from consideration, for example, is the extensive work of Hall (1991) on the change process and the important work done by Popkewitz, Tabachnick, and Wehlange (1982) illuminating different kinds of change. The organizational literature in sociology, political science, and psychology also are rich resources for informative work on educational organizations and change which Sarason does not cite. These omissions seem particularly notable in light of his recommendation that individuals from the disciplines should be involved in the reconceptualization of education and its organization.

\section{The Culture and Change}

Although individual, political, and organizational factors are important, it may be cultural factors and our approach to them that will determine if we are able to effect lasting change in education. Change may have become a ritual for us and our rhetoric a symbol, each with little substantive meaning. Sarason suggests we get behind the ritual and rhetoric and examine what it will mean for teacher educators truly to change the way teachers are prepared. As Sarason strongly argues, not only will there be multiple clashes of cultures - between schools and human services, education and the disciplines, home and school, schools and universities we may, in our attempt to change education, be threatening our own deeply embedded culture. He draws a distinction between educating and teaching, and suggests how fundamentally different these concepts are in relation to how we do our work. He suggests we must help our students develop conceptual and attitudinal bases for altering the realities of schools. We do not have to be overly familiar with the literature on conceptual and attitudinal change to know how difficult a task that is. Sarason reminds us to begin to address the taken-for-granted assumptions that limit our own way of knowing - assumptions that are the foundation for the culture in schools of education.

Sarason suggests that, as agents of a professional culture, we must acknowledge the moral responsibilties we have as teacher educators, just as we must help our own students to assume moral responsibility for the students they teach. Sarason also reminds us that teachers must be prepared to "look both inward and outward, a stance that makes discovery and growth possible" (p. 136). We must prepare teachers who will continue to grow. They must not only accept their own growth and the uncertainty that is a result, but they must seek it out. Sarason encourages us to consider if we even talk about this in our programs beyond a vague discussion of the growth of knowledge. Do we talk about the growth and development of our students as human beings: growth in how they know, in how they assume responsibility for students in their care, or growth in the organization that frames their professional work? As Dewey might ask us, If education is not about growth and development then what is it about? Sarason's questions push us to ask why our answers to such questions have been so limited.

An important issue that Sarason continues to raise is if the culture in schools of education supports the kind of culture we would like to see in the schools. Are all participants in schools of education perceived as learners? Are we sensitive to both our students' learning and to our own learning? Are we providing our students with opportunities to come to know that "abstract knowledge and concrete experience should always be seen in relation to each other. In what one does and how one does it, there is always the possibility of inconsistency between abstract principles and actions" (p. 130). Sarason further suggests that:

the would-be educator cannot do this on his or her own. It requires someone who has supervision. It also requires forums in which they come to understand that what they have learned will not be easily applied or even warmly welcomed in the real schools in which they will start their independent, professional careers. (p. 130) 
We must assure ourselves that we are preparing all of us for this eventuality.

\section{Conclusions}

One of the primary strengths of Sarason's thesis is his framing of change as an issue of primary prevention rather than repair or secondary prevention. He does not deny the need for all three approaches; rather, he chooses to draw our attention to what is needed to create schools that nurture learning, growth, and personal and intellectual change for both students and educators. Although his emphases on the need for a long-term approach to change and the development of a keen understanding of the complexity of change has been said by others, Sarason's own history of advocating change gives a great deal of weight to his argument. In contrast, his failure to reference or to acknowledge much of the work that teacher educators and other scholars have accomplished in regard to many of his recommendations is a shortcoming. Regardless of how one feels about the Holmes Group report (1986) or the Carnegie report on teacher preparation (1986), they have generated significant discussion leading to many in-depth debates of the same issues addressed by Sarason. A stronger book would have provided insight into his thinking on these debates and on the larger literature of teacher education.

As a psychologist, Sarason's focus is on individuals. Although he addresses the political, cultural and social factors in change, the organizational barriers that we will need to overcome are discussed in a very limited way. Whether we see organizational change as primarily a political process, a cultural transformation, or an interaction between individuals and the structure of the organization, organizational barriers to change will be significant and must be considered - particularly when we are dealing with an organization as resistant to change as education seems to be. I wish that these factors had been addressed more explicitly.

Nevertheless, as Sarason has suggested for at least the last two decades, if we become more thoughtful about change, perhaps we will have a chance for success. To truly change schools we need to change people, governance, power relations, organizational structures, and basic as- sumptions. These changes rest on gaining a better understanding of the complex ways in which these factors are all interconnected. Unequivocally, key to any change in education is change in the way teachers are educated. Prospective teachers must be prepared in ways that help them understand these complex relationships and that provide them with the ability to balance work in schools as they are while changing them in substantive, systemic ways. This will not be easy as those who have attempted to do so are well aware. Sarason reminds us of the difficulty of the task facing us - how to prepare teachers who will become change agents. Although there currently may be no villains in the failure of the schools to educate all students effectively, to ignore our responsibilities for effecting substantive school change would be villainous.

Individuals reading this book must not be misled. It would be easy to dismiss what Sarason is saying because so much of it has been said before. What he adds to the conversation is so important but so subtle that it would be easy to miss. As Sarason reminds us, our own experiences can blind us to what is new. In assuming we know what he is saying, it is easy to miss how profound his additions are. The crucial understanding he helps us gain is the profound change in individuals that will be required if we hope to effect substantive change in the schooling process. "Changing the personal-psychological lifestyle of a single individual is no easy task. Effecting such change in many individuals embedded in a complicated human system is galactically more difficult" (p. 216).

Individuals change systems just as systems change individuals; keeping both in sight is the key. We must change the way teachers are prepared so that they can effect systemic change. This will not be easy, nor will it be quick. It will require systemic change in our own organizations. We must give up the quick fix for the hard work of substantive, revolutionary, complicated, frustrating, difficult change. As Sarason clearly indicates, we have no choice if we take seriously our moral obligations as educators.

\section{References}

Aikin, W. A. (1942). The story of the eight-year study with conclusions and recommendations. New York: Harper Collins. 
Carnegie Task Force on Teaching as a Profession. (1986). $A$ nation prepared: Teachers for the iwenty-first century. New York: Carnegie Forum on Education and the Economy. Deal, T. E., \& Kennedy, A. A. (1982). Corporate cultures. Reading, MA: Addison-Wesley.

Eisner, E. W. (1993). Forms of understanding and the future of educational research. Educational Researcher, 22(7), 5-11.

Hall, G. (1991, April). Local educational change process and policy implementation. A paper presented at the annual meeting of the American Educational Research Associaton, Chicago.
Holmes Group. (1986). Tomarrow's teachers: A report of the Holmes Group. East Lansing, MI: Holmes Group.

Popkewitz, T., Tabachnick, B., \& Wehlange, G. (1982). The myth of educational reform: A study of school responses to a program of change. Madison, WI: University of Wisconsin Press.

Schon, D. (1979). Generative metaphor: A perspective on problem-setting in social policy. In A. Ortony (Ed.), Metaphor and thought (pp. 254-282). Cambridge: Cambridge University Press. 